\title{
Desarrollo psicomotor de 0 a 4 años en infancia indígena. Revisión sistemática de la literatura
}

\author{
Psychomotor development from 0 to 4 years in indigenous children. \\ A sistematic literature search
}

\author{
Astudillo P. ${ }^{\mathrm{a}, \mathrm{e}}$, Alarcón A. M. ${ }^{\mathrm{b}, \mathrm{c}}$, Pérez S. ${ }^{\mathrm{g}, \mathrm{h}}$, Fernández F. ${ }^{\mathrm{c}}$, Carmona V. ${ }^{\mathrm{d}, \mathrm{f}}$, Castro M. ${ }^{\mathrm{b}}$, Alarcón S. ${ }^{\mathrm{b}}$
}

aDepartamento de Cirugía, Traumatología y Anestesiología, Universidad de La Frontera, Chile

bDepartamento de Salud Pública Universidad de La Frontera, Chile

'Programa de Magíster en Salud Pública, Universidad de La Frontera, Chile

¿Departamento de Metodología de las Ciencias del Comportamiento, Universidad de Barcelona, España

ePrograma Doctorado en Psicología, Salud y Calidad de Vida, Universidad de Girona, España

fPrograma de Doctorado en Psicología Clínica y de la Salud. Universidad de Barcelona, España

qUniversidad Academia de Humanismo Cristiano, Santiago, Chile

hPrograma de Doctorado en Antropología y Comunicación, Universidad Rovira i Virgili, Tarragona, España

Recibido el 21 de agosto de 2017; aceptado el 20 de marzo de 2018
Palabras clave: Grupos etnicos; Infancia; Coordinación sensorio motora; Desarrollo psicomotor 


\begin{abstract}
Introduction: The objective of this study was to evaluate published articles regarding the development of indigenous children aged 0 to four years. Subjects and Method: Systematic literature search. Participants: Primary studies with populations of indigenous children aged 0 to four years. Type of studies: Primary studies with qualitative or quantitative methodologies published in the last ten years until November 2015. Databases: MEDLINE, Digital Library of the University of Girona: CERCADOR, EMBASE, Scielo. Search strategy: sensitive and specific. Free terms, MeSH, and Boolean. Results: Nine articles remain for analysis. There are six central subjects related to intracultural patterns of expected development in indigenous childhood: 1) physical, 2) language, 3) socio-cognitive, 4) emotional, 5) teaching-learning, 6) psychosocial, which reveal the existence of categories of sociocultural and spiritual contents. There is no defined period of time associated with the education. Learning is through observation and participation. Development is understood as a whole, intertwining the social, cultural, natural and spiritual. Conclusion: Spirituality and nature are at the center. Time as a goal to gain skills does not have a cultural function to demonstrate the acquisition of the inherent values to the culture. To base the assessment of development exclusively on psychomotor development as monitoring guide is insufficient to assess the integrality and complexity of the advances, abilities, and skills of indigenous children.
\end{abstract}

\section{Keywords:}

Ethnic groups; infant; psychomotor performance; psychomotor development

\section{Introducción}

Son denominados pueblos indígenas a los habitantes de un determinado territorio ancestral, cuyas condiciones sociales, culturales y económicas los distinguen de otras secciones de la comunidad nacional. También son denominados pueblos indígenas a aquellos descendientes de las poblaciones que habitaban una región geográfica específica, ya sea en el momento de la conquista, la colonización o el establecimiento de las fronteras del estado actual; quienes conservan sus propias instituciones sociales, económicas, culturales y políticas ${ }^{1,2}$. La infancia indígena se refiere a un período de la vida de un niño o niña en el contexto de una comunidad cultural indígena, que se extiende a través de varias generaciones con diversos roles y prácticas, $y$ que además posee una identidad étnica dinámica que se encuentra en constante cambio y construcción ${ }^{3,4}$. El estudio de la infancia indígena ha sido abordado predominantemente desde la óptica de la cultura dominante, sin considerar la carencia de pertinencia cultural de las conclusiones extraídas, razón por la cual se muestra un modelo de déficit, en el cual los modos culturales que difieren en las prácticas de los grupos dominantes son juzgados como menos adecuados sin haberlos examinado desde la perspectiva de los participantes de la comunidad ${ }^{5-8}$. Es por esta razón que en la década de 1960 surgen esfuerzos por dejar este modelo, considerando que su adscripción implica que las prácticas culturales del grupo dominante se tomen como la norma. Al respecto, Heckman ${ }^{9,10}$ señala que todavía a los niños del mundo se les mide y valora más por sus habilidades cognitivas que por sus destrezas socioemocionales; dejando fuera al conjunto de sociedades en que las habilidades sociales, la sintonía con la naturale- za, la noción de espacio, el escuchar y el silencio activo son valores fundamentales ${ }^{11-13}$. Chile no está ajeno a esta realidad, pero se han realizado esfuerzos para incorporar el enfoque Intercultural en la atención de la infancia indígena $\mathrm{a}^{4,14,15}$.

Por lo expuesto surge la pregunta que motiva nuestra búsqueda: ¿Qué se ha explorado respecto a los patrones intraculturales del desarrollo de niños y niñas de 0 a 4 años en el curso de la infancia indígena? Nos interesamos en este grupo de edad ya que la mayoría aún no se incorpora a la escolarización de la sociedad dominante, sino que mantienen la crianza en el seno de su comunidad.

Existe la necesidad de indagar en aspectos de vigilancia de la infancia temprana desde una perspectiva intracultural, de develar los aspectos cualitativos implicados en el desarrollo que consideren significativos y una búsqueda sistemática de la literatura es la metodología para explorar publicaciones existentes del tema. Abordar esta situación contribuye a reconocer y proteger la integridad de valores y prácticas sociales, culturales, religiosas y espirituales de estos pueblos en concordancia con la convención de pueblos indígenas ${ }^{1}$.

El objetivo de este estudio fue evaluar artículos publicados respecto a patrones intraculturales del desarrollo de niños y niñas de 0 a 4 años en el curso de la infancia indígena valorando aspectos físicos, sociales, cognitivos, emocionales, de aprendizaje y psicológicos.

\section{Sujetos y Método}

\section{Diseño y participantes}

Búsqueda sistemática de la literatura. Un proceso en fases que implica la identificación de los trabajos 
Infancia indígena - P. Astudillo et al

publicados (fuentes secundarias) sobre el desarrollo de la infancia indígena. Los participantes fueron estudios primarios cuya población correspondiera a niños y niñas de 0 a 4 años en 1 curso de infancia indígena. Se incluyeron estudios primarios cuyas metodologías fueran cualitativas o cuantitativas publicados los últimos 10 años, sin restricción idiomática. El rango de tiempo elegido se realizó en función de la necesidad de identificar y conocer los estudios recientes en la temática.

\section{Criterios de inclusión de los artículos}

Se consideraron artículos publicados en revistas de calidad académica que utilizan sistema de evaluación de pares caracterizada como "ciega". Se consideraron estudios que incluyeran grupos de Infancia indígena y en rangos de edad que fueran: desde recién nacido hasta infantes de 23 meses y en edad preescolar. Además, estudios que aportaran datos cualitativos o cuantitativos acerca de capacidades físicas, cognitivas, emocionales, psicosociales, lenguaje, socialización y aprendizaje. Solo se consideraron artículos publicados los últimos 10 años (enero de 2005 a noviembre de 2015), en humanos y con acceso a textos completos.

\section{Criterios de exclusión de los artículos}

i) Trabajos presentados en Congreso y Trabajos de Tesis, ya que no utilizan un sistema de evaluación de pares caracterizada como "ciega", y ii) Estudios de ciencias básicas, patología, morfología, fisiología, ge- nética, neurología y anatomía, ya que no son variables pertinentes al tema indagado.

\section{Metodología de búsqueda}

Pregunta de búsqueda: ¿Cuáles son los patrones intraculturales del desarrollo esperado en niños/as de 0 a 4 años en el curso de la infancia indígena? Fuentes de búsqueda: Artículos publicados en: MEDLINE, Biblioteca Digital de la Universidad de Girona: CERCADOR, EMBASE, Scielo. Estrategia de búsqueda: Se inicia una búsqueda sensible y luego específica utilizando: términos libres; término MeSH; y uso de términos boléanos (tabla 1). Fecha de búsqueda: 10 de noviembre de 2015.

\section{Proceso de selección}

Los artículos obtenidos de las bases de datos fueron ingresados a gestor de referencias, desde el cual los duplicados fueron removidos. Posteriormente, siguiendo las recomendaciones de Atkinson ${ }^{16}$, se realizó cribado por relevancia en dos etapas. Este cribado implica la utilización de un enfoque lo suficientemente amplio en la etapa inicial, que permita la inclusión de estudios potencialmente relevantes; y un estrechamiento progresivo a medida que los documentos se leen en profundidad. En la etapa inicial, dos investigadores de manera independiente realizaron una primera selección de artículos en base a la lectura de títulos y posteriormente en base a la lectura de los abstracts. Aquellos artículos que no cumplieron criterios de inclusión

Tabla 1. Comandos y límites para cada base de datos

\begin{tabular}{|c|c|c|}
\hline Base de datos & Comando de búsqueda & Límites \\
\hline PUBMED & $\begin{array}{l}\text { ((((((((childhood) OR early childhood) OR "Infant"[Mesh])) AND (((((((((()((((((culture) OR } \\
\text { cultural psychology) OR cultural context) OR ethnicity) OR social context) OR cultural } \\
\text { factors) OR Indigenous population) OR ethnic group) OR Indigenous) OR aboriginal) } \\
\text { OR "Culture"[Mesh]) OR "Ethnology"[Mesh]) OR "Ethnopsychology"[Mesh]) OR "Cul- } \\
\text { tural Characteristics"[Mesh]) OR "Social Environment"[Mesh]) OR "Cross-Cultural } \\
\text { Comparison"[Mesh]) OR "Population Groups"[Mesh]) OR "Ethnic Groups"[Mesh])) AND } \\
(((((((((\text { physical abilities) OR intellectual abilities) OR emotional capacities) OR language) } \\
\text { OR learning) OR psychomotor development) OR cognitive development) OR psychosocial } \\
\text { development) OR cognitive processes) OR socialization)) AND Humans[Mesh])) NOT ((((((mor- } \\
\text { phology) OR therapy) OR risk factors) OR (((((infection) OR tuberculosis) OR influenza virus) } \\
\text { OR ((((pedagogy) OR microbiology) OR bacteriology) OR ((((chemotherapy) OR radiation } \\
\text { therapy) OR oncology) OR (((((((((((pregnancy) OR genetic) OR disorder) OR basic sciences) OR } \\
\text { physiology) OR anatomy) OR pathology)) OR neurology)) OR premature))))) OR depression) }\end{array}$ & $\begin{array}{l}\text { Últimos } 10 \text { años, humano, } \\
\text { infancia, preescolar }\end{array}$ \\
\hline $\begin{array}{l}\text { Cercador: } \\
\text { Biblioteca de la } \\
\text { Universidad de } \\
\text { Girona }\end{array}$ & $\begin{array}{l}\text { (childhood OR Infant) AND (social context OR ethnic group OR Indigenous) AND (psychomo- } \\
\text { tor development OR psychomotor performance OR cognitive development OR psychosocial } \\
\text { development OR socialization) }\end{array}$ & Últimos 10 años. \\
\hline $\begin{array}{l}\text { EMBASE. } \\
\text { Vocabulario } \\
\text { controlado } \\
\text { Emtree }\end{array}$ & $\begin{array}{l}\text { 'childhood'/exp OR childhood OR 'infant'/exp OR infant AND (social AND context OR ethnic } \\
\text { AND group OR indigenous) AND (psychomotor AND ('development'/exp OR development) } \\
\text { OR cognitive AND ('development'/exp OR development) OR psychosocial AND ('develop- } \\
\text { ment'/exp OR development) OR 'socialization'/exp OR socialization) }\end{array}$ & $\begin{array}{l}\text { Últimos } 10 \text { años, infancia, } \\
\text { preescolar }\end{array}$ \\
\hline Scielo & $\begin{array}{l}\text { Desarrollo psicomotor, desarrollo infantil, estimulación, crianza, valores, saberes, intercultu- } \\
\text { ral, indígena, etnia, infancia, lactantes, niños. }\end{array}$ & Sin límites. \\
\hline
\end{tabular}


fueron removidos. En una segunda etapa, los restantes artículos fueron inspeccionados a texto completo y evaluados para su elegibilidad. Los desacuerdos derivados del proceso de selección fueron solventados por consenso, involucrando a un tercer revisor.

\section{Extracción de datos y plan de análisis}

Una herramienta de extracción de datos fue desarrollada y probada específicamente para este estudio. Por cada artículo, dos revisores obtuvieron datos acerca de las características de los participantes que incluyeron variables como: etnia, edad y variables del desarrollo. Y las características de los estudios: lugar, número de participantes, diseño del estudio (objetivos, estrategia de recolección de datos, plan de análisis), resultados, conclusiones. Los desacuerdos en el proceso de codificación fueron solventados por consenso.

\begin{tabular}{|c|c|c|c|}
\hline Fuente & $\begin{array}{l}\text { Artículos } \\
\text { obtenidos }\end{array}$ & $\begin{array}{l}\text { Artículos por } \\
\text { título atingente }\end{array}$ & $\begin{array}{l}\text { Artículos por } \\
\text { resumen atingente }\end{array}$ \\
\hline MEDLINE & 451 & 54 & 23 \\
\hline EMBASE & 120 & 16 & 6 \\
\hline SCIELO & 130 & 32 & 10 \\
\hline CERCADOR & 120 & 35 & 2 \\
\hline Total: & 821 & 137 & 41 \\
\hline
\end{tabular}

Posteriormente, a los resultados de los artículos, dos investigadores de manera independiente realizaron análisis textual inductivo asignando códigos a los patrones relacionados con aspectos físicos, lenguaje, sociales, cognitivos, emocionales, psicológicos, aprendizaje, para luego realizar un análisis de conjunto.

\section{Aspectos éticos}

Durante el análisis de los artículos primarios seleccionados se realizó enmascaramiento de autores, centros de estudio y títulos ${ }^{17}$ y evitar así un juicio previo al autor y permear el análisis con reflexiones más allá del contenido.

\section{Resultados}

Se obtuvo un total de 821 artículos, se seleccionan por título atingente a pregunta de búsqueda 137 (tabla 2 ). Se descartaron artículos por criterios como: Obesidad, Inmigrantes, Nutrición, Dolor, Autismo, Cuidados médicos en hogar, Inmunización, Salud oral, Mortalidad, Violencia entre otros; quedaron 41 artículos con resumen atingente. Luego se revisaron textos completos eliminando los que no aportan información atingente según criterios de inclusión, quedando 9 artículos (figura 1).

Los artículos incluidos se publicaron entre los años 2010 y 2014 e incluyeron un aproximado de 940 participantes (hubo estudios que no los reportan) pertenecientes a las siguientes etnias: Bushman (Sudáfrica), aborí-

Figura 1. Flujograma de se-

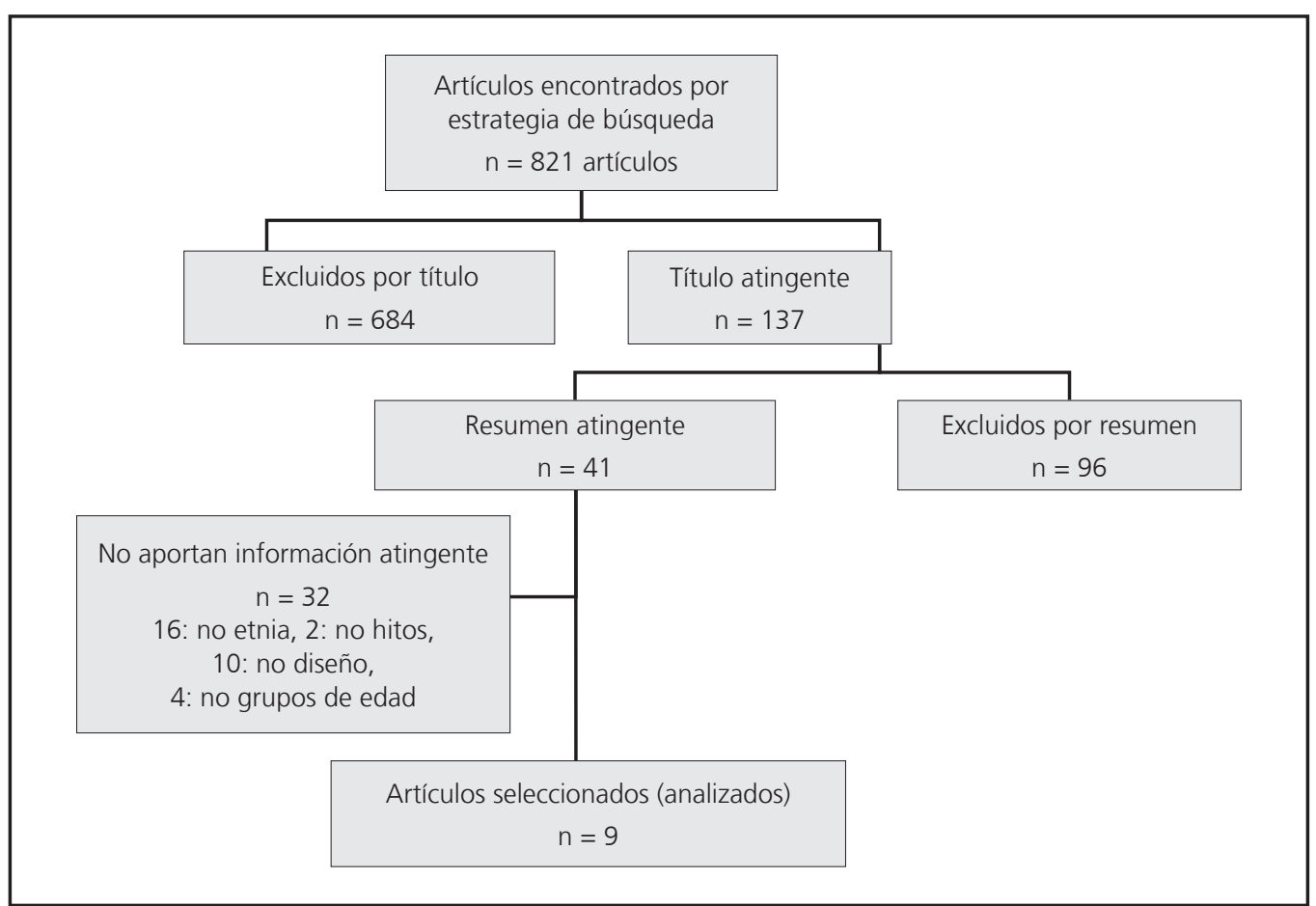


genes australianos, Nso o Banso (Noreste de Camerún), mayo-Yoreme (estado de Sonora y Sinaloa en el noreste de México), Tobas (asentamiento Toba a las afueras de la ciudad de Buenos Aires), Yucatecos-Mayas (México), Mapuche (localidades rurales de la región de La Araucanía), Gom y mbya (guaraní de Argentina), culturas tradicionales a pequeña escala en zonas rurales de Perú e India. Respecto a la metodología de los artículos, 5 corresponden a metodología cuantitativa (3 diseños transversales, 2 ensayos clínicos sin enmascaramiento) y 4 desarrollados con metodología cualitativa. La tabla 3 presenta una descripción de los artículos incluidos, mientras que la tabla 4 presenta las principales conclusiones de los estudios en torno a infancia indígena.

La mayoría de los estudios presentan en su introducción visiones de niños carentes de desarrollo; "retraso indígena y rural". Y en sus discusiones muestran un componente de valores socio-emocionales que chocan con lo occidental; el afecto y emoción en la interacción familiar como valor en la crianza.

Se presentan 6 temas centrales que se relacionan con: 1) lo físico; 2) el lenguaje; 3 ) lo socio-cognitivo; 4) lo emocional; 5) la enseñanza-aprendizaje; y 6) lo psicosocial.

Tabla 3. Artículos seleccionados según lugar, participantes y objetivos

\begin{tabular}{|c|c|c|c|c|c|}
\hline Autores & Etnia & Procedencia & Diseño & $\begin{array}{c}n \text { de } \\
\text { participantes }\end{array}$ & Objetivo \\
\hline $\begin{array}{l}\text { Nielsen } \\
\text { et al. }{ }^{19}\end{array}$ & $\begin{array}{l}\text { Bushman, } \\
\text { basarwas }\end{array}$ & $\begin{array}{l}\text { Pueblos nómadas del desierto } \\
\text { del Kalahari (Botswana y } \\
\text { Namibia), en África }\end{array}$ & $\begin{array}{l}\text { Ensayo clínico } \\
\text { sin enmascara- } \\
\text { miento. }\end{array}$ & $\begin{array}{l}61 \text { niños de } \\
3 \text { a } 5 \text { años }\end{array}$ & Explorar capacidades de innovación \\
\hline $\begin{array}{l}\text { D'Aprano } \\
\text { et al. }{ }^{21}\end{array}$ & $\begin{array}{l}\text { Aborígenes } \\
\text { australianos }\end{array}$ & Australia & $\begin{array}{l}\text { Corte } \\
\text { transversal }\end{array}$ & $\begin{array}{l}124 \text { niños de } \\
3 \text { a } 7 \text { años }\end{array}$ & $\begin{array}{l}\text { Aplicar la escala Brigance develop- } \\
\text { ment como instrumento para la iden- } \\
\text { tificación de niños y niñas aborígenes } \\
\text { australianos en riesgo del desarrollo }\end{array}$ \\
\hline $\begin{array}{l}\text { Teiser } \\
\text { et al. }{ }^{20}\end{array}$ & Nso (Banso) & Noreste de Camerún, África & $\begin{array}{l}\text { Ensayo clínico } \\
\text { sin enmascara- } \\
\text { miento }\end{array}$ & $\begin{array}{l}43 \text { lactantes de } \\
9 \text { meses }\end{array}$ & $\begin{array}{l}\text { Evaluar la imitación diferida con un } \\
\text { modelo adulto o bien un niño mayor }\end{array}$ \\
\hline $\begin{array}{l}\text { Vera } \\
\text { et al. }{ }^{22}\end{array}$ & Mayo-yoreme & $\begin{array}{l}\text { Estado de Sonora y Sinaloa en } \\
\text { el noreste de México }\end{array}$ & $\begin{array}{l}\text { Corte transver- } \\
\text { sal }\end{array}$ & $\begin{array}{l}100 \text { madres con } \\
\text { hijos de } 1 \text { a } 5 \\
\text { años de edad }\end{array}$ & $\begin{array}{l}\text { Identificar prácticas de estimulación y } \\
\text { promoción de desarrollo en la comu- } \\
\text { nidad Mayo. Conocer variables que in- } \\
\text { tervienen en la crianza y el desarrollo }\end{array}$ \\
\hline Hecht ${ }^{23}$ & Tobas & $\begin{array}{l}\text { Asentamiento Toba a las } \\
\text { afueras de la ciudad de } \\
\text { Buenos Aires, Argentina }\end{array}$ & Etnográfico & No reportada & $\begin{array}{l}\text { Sistematizar el papel de las prácticas y } \\
\text { los usos de la lengua toba y el español } \\
\text { durante la socialización de los niños } \\
\text { en distintas etapas de la niñez }\end{array}$ \\
\hline $\begin{array}{l}\text { Salomo } \\
\text { et al. }{ }^{18}\end{array}$ & $\begin{array}{l}\text { Yucatecos y } \\
\text { mayas }\end{array}$ & $\begin{array}{l}\text { Dos pequeños pueblos vecinos } \\
\text { cerca de la ciudad Chemax } \\
\text { en la Península de Yucatán } \\
\text { (México) }\end{array}$ & $\begin{array}{l}\text { Utiliza estrate- } \\
\text { gias cualita- } \\
\text { tivas para la } \\
\text { recolección de } \\
\text { datos y análisis }\end{array}$ & $\begin{array}{l}16 \text { lactantes de } \\
11 \text { meses y } 29 \\
\text { días }\end{array}$ & $\begin{array}{l}\text { Observar actividades diarias de lac- } \\
\text { tantes y sus interlocutores para poner } \\
\text { a prueba la presencia y la frecuencia } \\
\text { de las acciones conjuntas triádicas y } \\
\text { gestos deícticos }\end{array}$ \\
\hline $\begin{array}{l}\text { Quilaqueo } \\
\text { et al. }{ }^{24}\end{array}$ & $\begin{array}{l}\text { Mapuche. } \\
\text { Kimches (Sabios). } \\
\text { Poseen saberes } \\
\text { educativos } \\
\text { mapuche }\end{array}$ & $\begin{array}{l}\text { Comunidades ubicadas en tres } \\
\text { áreas territoriales: Wenteche, } \\
\text { Nagchey, Pewenche. La } \\
\text { Araucanía, Chile }\end{array}$ & $\begin{array}{l}\text { Investigación } \\
\text { educativa, } \\
\text { desde una } \\
\text { perspectiva } \\
\text { cualitativa }\end{array}$ & $\begin{array}{l}16 \text { Kimches de } \\
\text { localidades } \\
\text { Rurales que ha- } \\
\text { blan de niños y } \\
\text { niñas mapuche. }\end{array}$ & $\begin{array}{l}\text { Contribuir con el debate } \\
\text { epistémico de contenidos educativos } \\
\text { indígenas de educación intercultural }\end{array}$ \\
\hline $\begin{array}{l}\text { García } \\
\text { Palacios } \\
\text { et al. }{ }^{25}\end{array}$ & $\begin{array}{l}\text { Niños y niñas } \\
\text { mbyà-guaraní y } \\
\text { tobas/qom }\end{array}$ & $\begin{array}{l}\text { Mbyà-guaraní de Misiones y } \\
\text { tobas/qom de Gran Chaco y } \\
\text { Buenos Aires, Argentina }\end{array}$ & $\begin{array}{l}\text { Revisión de } \\
\text { fuentes etno- } \\
\text { gráficas }\end{array}$ & No reportada & $\begin{array}{l}\text { Documentar el modo en que se ha } \\
\text { aludido a la infancia indígena en las } \\
\text { fuentes etnográficas argentinas. Se } \\
\text { revisa cuál es el rol que ocupan los } \\
\text { niños y cómo son presentados }\end{array}$ \\
\hline $\begin{array}{l}\text { Callaghan } \\
\text { et al. }{ }^{26}\end{array}$ & $\begin{array}{l}\text { Perú rural } \\
\text { (descendencia } \\
\text { inca) y aborígenes } \\
\text { de la India. }\end{array}$ & $\begin{array}{l}\text { San Pedro de Sano y cuatro } \\
\text { pueblos cercanos. Valle de } \\
\text { Montaro en el altiplano } \\
\text { andino provincia de Junín, } \\
\text { Perú. Seis aldeas en los } \\
\text { alrededores de Srikakulam, } \\
\text { distrito de Krishna, India }\end{array}$ & $\begin{array}{l}\text { Ensayo clínico } \\
\text { sin enmascara- } \\
\text { miento }\end{array}$ & $\begin{array}{l}\text { 232/348 (Perú/ } \\
\text { India). } \\
\text { Madres de niños } \\
\text { de } 1 \text { a } 3 \text { años. }\end{array}$ & $\begin{array}{l}\text { Se evaluaron habilidades sociocog- } \\
\text { nitivas tales como: imitación natural, } \\
\text { ayudar a otros, mirada después de } \\
\text { barrera, señalamiento, atención con- } \\
\text { junta, tareas simuladas, colaboración } \\
\text { y símbolos pictóricos }\end{array}$ \\
\hline
\end{tabular}




\section{Tabla 4. Artículos seleccionados y principales conclusiones}

\begin{tabular}{|c|c|}
\hline Autores & Conclusión \\
\hline Nielsen et al. ${ }^{19}$ & $\begin{array}{l}\text { La capacidad para la innovación en la fabricación de herramientas está gravemente limitada en los niños antes de } \\
\text { los años de la enseñanza escolar. }\end{array}$ \\
\hline 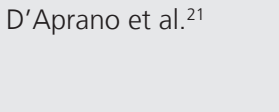 & $\begin{array}{l}\text { Idioma, pertinencia cultural y forma de administración limitan el uso de la escala de desarrollo Brigance. Se requie- } \\
\text { re mejorar y adaptar una herramienta para guiar un desarrollo culturalmente sensible y apropiado dentro de las } \\
\text { comunidades. }\end{array}$ \\
\hline Teiser et al. ${ }^{20}$ & $\begin{array}{l}\text { A los nueve meses de edad niños y niñas de diversos orígenes culturales no solo aprenden por imitación, sino tam- } \\
\text { bién muestran similares patrones de imitación con respecto a la edad del modelo y dificultad de la tarea, con una } \\
\text { ventaja para el modelo adulto. }\end{array}$ \\
\hline Vera et al..$^{22}$ & $\begin{array}{l}\text { Se requiere un modelo de crianza para zonas indígenas anclado en el concepto de "conciencia étnica". Para lograrlo } \\
\text { existen tres variables: a) lo afectivo-emocional en la interacción familiar, incluyendo el uso del susto y el miedo a } \\
\text { través de mitos étnicos y la regulación de afectos, a fin de moldear conductas socialmente aceptables. b) Observación } \\
\text { de la relación del niño con el entorno sin restricciones o supresión de riesgos o peligros. c) Observación y análisis de } \\
\text { la inducción al niño en rituales y mitología étnica. Esta triada solo tiene sentido social en un entorno que coloque } \\
\text { la lengua de origen en un lugar de privilegio frente a la lengua dominante; y la familia y el grupo social se sientan } \\
\text { orgullosos de su uso y resguardo. }\end{array}$ \\
\hline $\mathrm{Hecht}^{23}$ & $\begin{array}{l}\text { La experiencia que viven los niños en la relación con las lenguas no solo es cuantitativamente acumulativa, es decir, } \\
\text { a mayor edad, mejor conocimiento y desempeño lingüístico; sino también cualitativamente diferentes a las de un } \\
\text { adulto; dado que en distintos momentos de la vida se experimentan usos, funciones y necesidades diferentes en } \\
\text { relación con las lenguas. Se debe tener precaución con los diagnósticos sociolingüísticos que aseguran que la falta } \\
\text { de competencia lingüística de los niños es un claro signo de un irreversible proceso de desplazamiento lingüístico. }\end{array}$ \\
\hline Salomo et al. ${ }^{18}$ & $\begin{array}{l}\text { El desarrollo tiene lugar dentro de la actividad sociocultural y, por ende, para beneficiarse y participar en ella se ne- } \\
\text { cesitan habilidades de comunicación. La aparición de gestos prelingüísticos se encuentra mediada por la experiencia } \\
\text { de interacción social. El análisis de las diferencias de los insumos naturales en diferentes entornos socioculturales } \\
\text { proporciona evidencia cuasi-experimental para la aparición de gestos deícticos prelingüísticos en la infancia. Las } \\
\text { acciones de los demás estructuran la ontogenia de la comunicación humana y la cognición social desde el principio. }\end{array}$ \\
\hline Quilaqueo et al. ${ }^{24}$ & $\begin{array}{l}\text { Se requiere una educación intercultural fundamentada en una epistemología que considere los conocimientos } \\
\text { educativos familiares. La escuela basada en un enfoque educativo intercultural debiera implementar una formación } \\
\text { abierta y reflexiva que permita a las nuevas generaciones mapuche y no mapuche formarse para dialogar con el otro } \\
\text { en un marco de respeto de las personas, su pertenencia social y cultural. Se necesita continuar avanzando en la cons- } \\
\text { trucción epistemológica de un cuerpo de conocimientos que sustente la formación de ciudadanos interculturales. }\end{array}$ \\
\hline García Palacios et al. ${ }^{25}$ & $\begin{array}{l}\text { Las formas definidas como "de la edad adulta" no son vistas como procesos en transformación. Son los niños } \\
\text { los que quieren, o deben, ser como los otros, incorporando sus saberes. Esto se debe a una visión finalista de los } \\
\text { procesos de socialización que habilita a las investigaciones a no incluir las transformaciones en las apropiaciones } \\
\text { infantiles. Esta perspectiva cosifica a la infancia ya que los niños son considerados pasivos y su única función consiste } \\
\text { en recibir las pautas culturales. A su vez, también se cosifican estas pautas culturales ya que se presentan como algo } \\
\text { ya acabado que se transmite a los niños sin sufrir mayores transformaciones en el proceso. }\end{array}$ \\
\hline Callaghan et al. ${ }^{26}$ & $\begin{array}{l}\text { Los niños pequeños en todos los entornos culturales obtienen, alrededor de la misma edad, cantidades suficientes } \\
\text { de los tipos correctos de experiencia social para desarrollar sus habilidades sociales cognitivas más básicas para } \\
\text { interactuar con otros y participar en la cultura. Mientras que la adquisición de habilidades más específicas para su } \\
\text { uso en prácticas que involucran símbolos y artefactos dependen más de las experiencias de aprendizaje específicas. }\end{array}$ \\
\hline
\end{tabular}

\section{1) Lo físico}

Caminar como un hito de independencia ya que puede trascender límites del hogar y control paterno, con ello una mayor socialización con otras personas que no pertenecen al núcleo familiar directo. "Libre circulación entre las casas y cumplen misión de emisarios, pueden entrar y salir de las mismas sin pedir permiso" (Tobas) ${ }^{23}$.

\section{2) El lenguaje}

Primera etapa de la infancia culmina con el habla. "el habla puede ser un instrumento para marcar etapas en ciclo de la vida porque se vincula con otras referencias e identificaciones, más allá del uso de uno u otro recurso léxico, gramatical o fonológico. En este caso, esta primera etapa del ciclo vital concluye cuando comienza a hablar" (Tobas) ${ }^{23}$; No utilizan la dirección de su casa. "No hay números de casa o nombre de calle. Describen sus casas $y$ lugares de interés cercano, cuando se les pregunta su dirección" (Ab. Australianos) ${ }^{21}$; Identificar edad o apellido no es importante. "Muchos padres no sabían la edad exacta de su hijo" (Ab. Australianos $)^{21}$; Señalizar apuntando con el dedo índice desde los 9 a 13 meses. "Lactantes que apuntaban con el dedo índice fueron en grupo de mayor edad, superior a 12 meses" (Yucatecos y mayas)" "las madres informaron que sus bebés comen- 
zaron a apuntar alrededor de 9-10 meses de edad" (Perú e India $)^{26}$; Comprender palabras a los 11-12 meses y producir palabras alrededor de los 16 meses. "los bebés comenzaron a comprender palabras alrededor 11-12 meses de edad y comenzaron a producir palabras alrededor de 16 meses" (Perú e India) ${ }^{26}$.

\section{3) Lo socio-cognitivo}

Actividades diarias estructuradas en torno a actividades de los padres. "Las actividades diarias se estructuraron por el trabajo de sus padres y no debe ser interrumpido por los niños. Poca atención en cómo los niños pasaron su tiempo, casi no hay interferencia del adulto" (Yucatecos y mayas $)^{18}$. "Aprenden sus futuras ocupaciones a través de la acción, la imitación y el juego" (Mbyaguaraní y tobas $)^{25}$; Abuelos principales educadores. " $\mathrm{La}$ validez de los abuelos se relaciona con su participación en la formación de las nuevas generaciones, su ausencia se entiende como limitación de la formación de los niños" (Mapuche) ${ }^{24}$; Ayuda a otros se manifiesta a los 18 meses de edad. "Responder a las señales de que otros necesitan ayuda está en marcha a los 18 meses de edad" (Perú e India) ${ }^{26}$; Mirada después de la barrera a los 12 meses. "Se arrastraron detrás de la barrera cuando no pudieron ver lo que el experimentador estaba mirando, esta es una habilidad demostrada por la mayoría de los bebés de 12 meses" (Perú e India) ${ }^{26}$; Colaboración a los 17-20 meses. "comenzaron a demostrar sensibilidad a la naturaleza colaborativa de los juegos dentro de un rango de edad considerado típico para esta tarea" (Perú e India $)^{26}$; Atención conjunta e intercambio comunicativo de 8-13 meses. "participan igualmente en episodios de atención conjunta con una mujer experimentadora que interactuó con ellos en un intercambio comunicativo, $y$ prácticamente todos de 8-13 meses de edad" (Perú e India ${ }^{26}$; Símbolo pictórico: comprensión y producción de símbolos pictóricos, (completar dibujos, interés en la figura de perros, gatos, autos) entre 2 a 3 años. "Completar dibujos, comprenderla, producirla, dibujar objeto frente al niño, 2 a 3 años. En los niños "occidentales" las interacciones sociales que implican este tipo de simbolos son en una tasa más alta que los niños peruanos" (Perú e India) 26. Tareas simuladas a los 45.8 meses. "Comenzaron a realizar acciones específicas, tareas simuladas, siguiendo la demostración a los 45,8 meses" (Perú e India $)^{26}$; Identificación de animales de la zona; a los 36 meses. "Niños de 3 años de edad eran capaces de nombrar aves, peces y serpientes" (Ab. Australianos) $)^{21}$.

\section{4) Respecto al desarrollo emocional}

Lactancia; método para calmar angustia del bebé. "Los padres definen su rol de cuidador en términos de garantizar seguridad y bienestar del bebé, respondiendo a sus necesidades y deseos, calmarlo a través de lactancia frecuente" (Bushman, basarwas) ${ }^{18}$; Importancia de la evaluación social de la familia y el respeto a la cultura por parte de la comunidad. "Pertenecer a una familia bien evaluada social y culturalmente es un apoyo vital, ya que incide en la calidad de la formación de los niños y jóvenes. Esto se observa cuando se expresa: "yo tengo tres hijos, ellos están casados, son respetuosos, no son tímidos, no son pobres y no deben serlo porque tienen buena ascendencia" (Mapuche) ${ }^{24}$.

\section{5) La enseñanza-aprendizaje}

Crear juguetes de objetos encontrados en el entorno. "Tiene mayor necesidad de fabricar sus propios juguetes y ser menos propensos a recibir instrucción guiada directa de sus padres" (Bushman, basarwas) ${ }^{19}$; Imitar de forma natural las rutinas de cuidado personal, tareas domésticas,"Los bebés de 9 meses de diversas procedencias culturales no sólo aprenden a través de la imitación, sino también muestran patrones similares con respecto a la edad del modelo y la dificultad de la tarea"(Nso $)^{20}$; Aprendizaje basado en la independencia, la autonomía y cuidado comunitario. "Consigue mayor independencia al poder trascender los limites del hogar y el control paterno, incluso un joven padre comentó "acá tenemos treinta y dos casas para cuidar a los chicos»" (Tobas) ${ }^{23}$; Imitar la utilización de objetos a partir de los 6 a 10 meses de edad. "A los 6 meses muestran capacidad de adquirir conocimientos necesarios para utilizar nuevos objetos copiando a otros" (Bushman, basarwas) 19; "Niños comenzaron a imitar alrededor de los 10 meses. Las imitaciones más frecuentemente reportadas vinieron de tareas domésticas"26; En tareas difíciles es más frecuente la imitación con modelos adultos" imitación con respecto a la edad del modelo y dificultad de la tarea, con una ventaja para el modelo adulto" (Nso) ${ }^{20}$; Imitación estandarizada entre los 12 y 15 meses "estaban imitando al experimentador y la madre, mostraron acciones familiares utilizando materiales comunes en el entorno del niño" (Perú e India) ${ }^{26}$; Baja capacidad en la innovación de fabricación de herramientas "Independientemente de sus antecedentes culturales, todos los niños pequeños evaluados mostraron niveles significativamente bajos en las innovación de herramientas" (Bushman, basarwas) ${ }^{19}$.

\section{6) Lo psicosocial}

Suelen omitir castigos corporales o verbales para enseñar normas culturales, educación hacia la no violencia a otros. "También resalta la poca hostilidad en las relaciones entre pares lo cual constituye otro aspecto culturalmente transmisible: la no violencia al interior de los grupos” (Mbya-guaraní y tobas) ${ }^{25}$; Técnica de enseñanza de evitación y escape. "Utilizan técnicas de enseñanza-aprendizaje basadas en evitación y escape, utilizan el castigo para mantener a sus hijos sujetos a normas $y$ reglas de la familia y comunidad" (Mayo-yoreme)22; Uso del enojo, vergüenza y miedo como práctica para el de- 
sarrollo socio moral. "Uso del enojo, vergüenza y miedo como ejercicio socio moral de reconocimiento de valores, rituales y premisas, práctica recurrente para lograr que los niños lleguen a convertirse en "personas listas". Ser "listos" implica el desarrollo socio-moral, entendimiento de reglas y normas de actuación en un mundo que se torna distinto y está asediado por una sociedad que lo asimila y lo homogeniza" (Mayo-yoreme) ${ }^{22}$; Incluirlos en todos los niveles de la vida familiar y comunitaria; a toda edad (matrimonios, defunciones, ceremonias religiosas) "Los niños no están separados de la vida de sus mayores; se incluyen en todos los niveles de la vida familiar y comunitaria. Bebés y niños/as pequeños/as también asisten a la celebración de los hitos de la familia, como matrimonios, defunciones y ceremonias religiosas" (Perú $e$ India $)^{26}$; Respeto entre parientes: contenido central en la educación familiar. "Contenidos centrales en la educación familiar es el yamün, al respeto entre parientes, valor a la relación de parentesco"(Mapuche) ${ }^{24}$; Contenidos educativos de la ascendencia paterna "küpan, vinculado a su lugar de asentamiento y al estatus social" (Mapuche $)^{24}$; Contenidos educativos del origen territorial y familiar "tuwün, se relaciona con conocimientos sobre las características de su territorialidad y la interacción de las personas con el medio natural, el medio familiar y cultural" (Mapuche) ${ }^{24}$; Contenidos de la organización del ciclo anual "relacionado con los ciclos de la naturaleza y las actividades sociales y culturales de la familia" (Mapuche) ${ }^{24}$.

\section{Discusión}

Las comunidades indígenas del presente estudio poseen rasgos en común que vale la pena considerar, sin embargo, no se pretende unificar patrones de desarrollo, sino que exponer las características que se narran en los artículos respecto a la infancia indígena. África, India, Oceanía y América comparten un territorio que sufrió conquistas, mayoritariamente por europeos. Cuentan con una identidad propia y se identifican como grupo cultural distinto. Con el espacio geográfico poseen un apego al territorio ancestral ya que es la tierra su principal fuente de subsistencia, hay un apego a los fenómenos de la tierra. Son poseedores de una lengua indígena comúnmente distinta a la lengua nacional, practican una vida en comunidad en donde se proyecta el bienestar colectivo y una experiencia común de los pueblos indígenas del mundo, sus desventajas sociales y económicas ${ }^{19,27,28}$.

Si bien los resultados se presentan en términos de áreas específicas, los patrones del desarrollo develados se respaldan en una lógica de conocimiento en directa relación con sus aspectos territoriales, culturales, espirituales y sociales. En sociedades indígenas la vida es factible de dividir en pequeños ámbitos para su desarrollo, pero éstos siempre estarán vinculados. Así, la evaluación de cualquier momento de la vida es en relación a ese elemento íntegro y no respecto de áreas específicas y aisladas. De esta forma, el desarrollo es comprendido como un todo, en el cual se entrelaza lo social, cultural, natural y espiritual ${ }^{3,29-33}$.

Los resultados de la búsqueda muestran la existencia de categorías de contenidos socioculturales y espirituales que pueden aportar al cuestionamiento de los contenidos de la valoración del desarrollo de niños/as de 0 a 4 años en el curso de la infancia indígena centrándose en categorías diagnósticas del desarrollo psicomotor. Este cuestionamiento se relaciona con la valoración de la complejidad de los progresos, habilidades y destrezas de los niños y niñas, requiriéndose un diálogo de saberes entre el conocimiento sociocultural indígena y los contenidos específicos de dichas valoraciones. Se observa una línea valórica que conduce a la formación de niños y niñas rectas, justas, respetuosas, con reglas; ser buenas personas. Coincide con la visión Mapuche, en ser Newenche; Norche; Kimche; Küme$c h e^{34}$. El sentido del avergonzar, que tenga respeto, que evite atrevimiento tiene relación con el término Yewen, del mapudungun, traducido al castellano como "respeto", pero también como "vergüenza" 35 .

No se muestra una temporalidad definida asociada a la formación, el tiempo es un aspecto inherente de los acontecimientos y no se divide en unidades separadas. Como tal, el presente se extiende a través del pasado y del futuro, y no puede ser separado de ellos ${ }^{36,37}$.

En base a nuestros hallazgos, la complementación en la evaluación del desarrollo es un desafío que requiere de la comprensión del contacto intercultural como un enriquecimiento y una oportunidad para el desarrollo de las sociedades y personas en torno al diálogo y la diversidad. La percepción y vivencia de la diversidad permiten al ser humano descubrir, construir y reafirmar la propia identidad ${ }^{38}$. Como lo señalara J. Heckman', ninguna de las formas de valoración del desarrollo del niño ha incorporado variables de tipo cultural o ha considerado que las etapas y exigencias socio-emocionales, espirituales y cognitivas difieren según el componente étnico y ontogénico del ser indígena.

Barbara Rogoff argumenta que el desarrollo humano debe ser entendido como un proceso cultural, no simplemente biológico o psicológico. Las personas se desarrollan como miembros de una comunidad, y su desarrollo solo puede comprenderse completamente mediante el examen de las prácticas y las circunstancias de sus comunidades ${ }^{3}$.

Este estudio tiene limitaciones necesarias de considerar. Dada la escasez de estudios en la temática, se incluyeron artículos con distintos diseños y reporte 
de resultados, por lo que fue necesario optar por una estrategia de análisis cualitativa. De igual forma, dada la diversidad cultural de los participantes, los patrones intraculturales del desarrollo han de considerarse en el contexto de la cultura a la cual pertenecen los infantes, razón por la cual hemos optado por su descripción. Futuras investigaciones requieren el estudio del desarrollo de la infancia indígena como proceso único e inherente a cada contexto particular, considerando sus particulares circunstancias.

En Conclusión, este estudio muestra que basar la valoración del desarrollo centrándose exclusivamente en categorías diagnósticas del desarrollo psicomotor como guía de vigilancia es insuficiente para valorar la complejidad de los progresos, habilidades y destrezas en el desarrollo de los niños/niñas indígenas. La integralidad del mundo indígena se concentra en la forma- ción de personas con valores propios de la cultura. La temporalidad como meta para la adquisición de destrezas no ejerce función cultural para demostrar la adquisición de estos valores. En consecuencia, programas que evalúan y estimulan el desarrollo bajo parámetros de otra cultura, una cultura dominante, promueve un modelo de parentalidad ajeno y se constituye en un factor causal de inequidad social.

\section{Financiamiento}

FONDECYT REGULAR 2015, № 1150833.

\section{Conflicto de intereses}

Los autores declaran no tener conflicto de intereses.

\section{Referencias}

1. ILO. Indigenous and Tribal Peoples Convention, 1989 (No. 169). Disponible en: goo.gl/Ytpcrw (accessed 27 july 2017).

2. ONU. Declaración de las Naciones Unidas sobre los derechos de los pueblos indígenas. Resolución aprobada por la Asamblea General 61/295; 2008. goo.gl/ Bdesb (accessed 27 july 2017).

3. Rogoff B. The cultural nature of human development, 1st ed. New york; 2003.

4. Sadler M, Obach A, Alarcón A, Vidal A, Astudillo P, Videla R. Pautas de crianza mapuche: "Significaciones, actitudes y prácticas de familias mapuches en relación a la crianza y cuidado infantil de los niños y niñas desde la gestación hasta los cinco años, 1st ed. Santiago de Chile; 2006.

5. Cole M, Bruner J. Cultural Differences and Inferences About Psychological Processes. American Psychological Association October 1997;20(10): Disponible en goo.gl/sCHfW7 (accessed 11 January 2017).

6. Moore S. The Young Child: Reviews of Research, Volume 3 ed. Washington DC; December 1982.

7. Mcloyd V, Randolph S. Secular trends in the study of Afro-American children: a review of Child Development, 1936-1980. Monographs of the Society for Research in Child Development 1985;(50). Disponible en goo.gl/uvE86y (accessed 20 january 2017).

8. McShane D, Berry J. Native North Americans: Indian and Inuit abilities. Irvine S, Berry J (eds). Cultural limits upon human assessment, 2nd ed. New York: Cambridge University Press; 1988. pp. 384-426.
9. Heckman J. Giving Kids a Fair Chance, 1st ed. Chicago: Boston Review Books; 2013.

10. Heckman J, Pinto R, Savelyev P. Understanding the Mechanisms Through Which an Influential Early Childhood Program Boosted Adult Outcomes. The American economic review October 2013;103(6). Disponible en http://bit. ly/2t3VaJW (accessed 13 March 2017).

11. Gentner D, Goldin-Meadow S. Language in mind: Advances in the study of language and thought, 1st ed. Cambridge Massachusetts: Massachusetts Institute of Technology press; 2003.

12. Haun D, Radolpf C, Janzen G, Levinson SC. Plasticity of human spatial cognition: spatial language and cognition covary across cultures. Cognition april 2011;(1). Disponible en http://bit.ly/2t2jWtV (accessed 20 March 2017).

13. Levinson SC, Wilkins D. Grammars of Space: Explorations in Cognitive Diversity, 1st ed. Cambridge: Cambridge University Press; 2006.

14. Pardo M, Armijo I. Validación cultural del contenido de la versión preliminar de un test de evaluación del desarrollo de niños de 0 a 6 años en construcción. En ponencia: Segundo Congreso Interdisciplinario de Investigación en Educación. 2012; Universidad de Chile. Disponible en http://bit.ly/2FCItIv (accessed 13 March 2017).

15. Quidel J, Pichinao J. Haciendo crecer personas pequeñas en el pueblo Mapuche. Temuco, Chile: Seremi de Educación Araucanía; 2002. Disponible en http://bit. ly/2CNh2sB (accessed 20 december 2016).

16. Atkinson K, Koenka A, Sánchez C, Moshontz H, Cooper H. Reporting standards for literature searches and report inclusion criteria: making research syntheses more transparent and easy to replicate. Research synthesis methods 2015;6(1). Disponible en http://bit. ly/2GQFsUp (accessed 20 April 2017).

17. Manterola C, Astudillo P, Arias E, Claros $\mathrm{N}$. Revisiones sistemáticas de la literatura. Qué se debe saber acerca de ellas. Cirugía Española 2013;91(3):149-155. Disponible en http://bit.ly/2EWo5Fn (accessed 10 September 2017).

18. Salomo D, Liszkowski U. Sociocultural Settings Influence the Emergence of Prelinguistic Deictic Gestures. Child development 2013;84(4):1296-1307. Disponible en http://bit.ly/2oDMi8h (accessed 10 january 2017).

19. Nielsen M, Tomaselli K, Mushin I, Whitend A. Exploring tool innovation: A comparison of Western and Bushman children. Journal of Experimental Child Psychology October 2014;126:384-394. Disponible en http://bit.ly/2F1 KrBg (accessed 11 Januari 2017).

20. Teiser J, Lamm B, Böning M, Graf F, Gudi H, Goertz C, Fassbender I, Freitag C, Spangler S, Teubert M, Lohaus M, Schwarzer C, Knopf M, Keller M. Deferred imitation in 9-month-old: How do model and task characteristics matter across cultures? International Journal of Behavioral Development 2014;38(3): http://bit.ly/2F1tfvP (accessed 12 January 2017).

21. D'Aprano A, Carapetis J, Andrews R. Trial of a developmental screening tool in remote Australian Aboriginal communities: a cautionary tale. Journal of Paediatrics and Child Health January 2014;47(1). http://bit.ly/2GSIGXp (accessed 12 January 2017).

22. Vera J, Torres Ma, Rodríguez C, 
Aguilera JP. Prácticas de estimulación y promoción del desarrollo infantil en la etnia Mayo. Psico-USF 2010;15(3):365377. Disponible en http://bit.ly/2CP1dl6 (accessed 13 January 2017).

23. Hecht A. Niñez y desplazamiento lingüístico: reflexiones acerca del papel del habla en la socialización de los niños tobas de Buenos Aires. Anthropologica 2009;27(27). Disponible en http://bit. ly/2oBWFta (accessed 13 January 2017).

24. Quilaqueo D, Quintriqueo S, Torres H, Muñoz G. Saberes educativos mapuche: aportes epistémicos para un enfoque de educación intercultural. Chungará 2014; 46(2). Disponible en http://bit. ly/2FEgsQT (accessed 20 January 2017).

25. García M, Enriz N, Hecht AC. Niños y niñas en las fuentes etnográficas sobre poblaciones indígenas (qom-mbya). Centro de Estudios Interdisciplinarios en Etnolingüística y Antropología Sociocultural 2014;(28). Disponible en http:// bit.ly/2CpKZmR (accessed 21 January 2017).

26. Callaghan T, Moll H, Rakoczy H, Warneken F, Liszkowski U, Behne T, Tomasello M. Early social cognition in three cultural contexts. Monographs of the Society for Research in Child Development 2011;76(2). Disponible en http://bit.ly/2t5kWxq (accessed 21 January 2017).
27. Ramírez C. Las comunidades indígenas como usuarios de la información. Investigación bibliotecológica 2007;21(43). Disponible en http://bit. ly/1hn6RQs (accessed 13 April 2017).

28. Mires A. Lo que cuento no es mi cuento: Cultura andina y tradición oral, 1st ed. Cajamarca: Abya yala publicaciones; 1996.

29. Quilaqueo D, Torres H. Multiculturalidad e Interculturalidad: Desafíos epistemológicos de la escolarización desarrollada en contextos indígenas. Alpha 2013;(37):285-300. Disponible en http://bit.ly/2oJeJ50 (accessed 08 March 2017).

30. Quilaqueo D. Saberes educativos mapuches: Racionalidad apoyada en la memoria social de los kimches. Atenea 2012;(505):79-102. Disponible en http:// bit.ly/2GQCVcP (accessed 25 March 2017).

31. Muñoz G. Ascendencia familiar y origen territorial, como contenido educativo en la socialización mapuche. Huerta N, Gusenbauer A. y Cárcamo L. Interculturalidad desde el sur: Demandas y Proyecciones en el Bicentenario. Editorial Universidad Austral de Chile. Valdivia, Chile. 2011;131-144.

32. Quintriqueo S, Muñoz G. Demandes éducation nelles socio historiques et éducation interculturelle en contexte mapuche. Salas R, Le Bonniec F. Les Mapuche a la mode, Modes d'existence et de résistanceau Chili, en Argentine et au-delà. L'Harmattan. Paris, France. 2015;95-121.

33. Rogoff B. Apprenticeship in Thinking Cognitive Development in Social Context, 1 st ed. New York: Oxford university Press; 1990.

34. Quilaqueo D. Valores educativos mapuches para la formación de persona desde el discurso de kimches. Estudios pedagógicos 2006;32(2):73-86. Disponible en http://bit.ly/2GNPcyP (accessed 13 March 2017).

35. Course M. Becoming Mapuche: Person and Ritual in Indigenous Chile, 1st ed.: University of Illinois Press; 2011.

36. Lacasa P. Contexto y desarrollo cognitivo. Entrevista a Bárbara Rogoff. Journal for the Study of Education and Development 1989;12(45):7-23. Disponible en http:// bit.ly/2F9RDPc (accessed 18 December 2016).

37. Rogoff B. Aprendices del pensamiento; El desarrollo cognitivo en el contexto social. $1^{a}$ edición. Ediciones Paidos, Barcelona, Buenos Aires, México. 1993.

38. Hirmas C. Educación y Diversidad Cultural: Lecciones desde la práctica innovadora en América Latina. Santiago de Chile: UNESCO; 2008. 